\title{
A Critical Appraisal of the Relevance of Field Work Practice in Social Work Education in Nigeria
}

\author{
Uche, Okala A. \\ Department of Social Work, University of Nigeria, Nsukka - Nigeria \\ Email: ucheokalaa@gmail.com \\ Uche, ljeoma B. \\ Department of Social Work, University of Nigeria, Nsukka - Nigeria \\ Email: blessijcarol@gmail.com \\ Eme, Okechukwu I. \\ Department of Public Administration, University of Nigeria, Nsukka - Nigeria. \\ Email: okechukwunncnt@gmail.com \\ Ebue, Malachy 0. \\ Department of Social Work, University of Nigeria, Nsukka - Nigeria \\ Email: malachy.ebue@unn.edu.ng
}

Doi:10.5901/mjss.2014.v5n27p1328

\section{Abstract}

Field work practice is a vital tool in moulding professional Social workers. Social work education has the primary aim of preparing the social work student for professional practice which focuses on the transaction between people and their social environment. This affects their ability to alleviate distress and realize individual as well as collective goals. The social worker assesses situations and plan interventions to facilitate and enhance the coping ability of people. This paper examines field work practice as a basis for social work education. The authors review extant training needs of students and conclude that field education is not radically different from the extant policies and has potential effect on professional development. If solution to the problem of ethical conduct is to be desired, it is essential to effectively utilize the knowledge in field education. Ultimately, rather than leaving the students on their own, the field instructors should be reckoned with in guiding the students as partners and collaborators.

Keywords: Appraisal, Education, Field work practice, Relevance, Social Work.

\section{Introduction}

Nigeria is at present faced with a myriad of social problems. These include poverty, unemployment, crime, terrorism, delinquency, destitution, drug and alcohol addiction, family instability and child abuse among others. The phenomena of urbanization, economic uncertainties and trans-culturalization are producing norm and value conflicts in our society. These in turn result to insecurity for individuals, groups and communities. It has also increased problems in interpersonal relationship.

The practice of social work demands as of necessity a lot of technical training. According to Ekpe (1997) social work education in Nigeria started to receive increasing attention in 1974 when the Federal Government promulgated the Social Development decree No. 12. This Decree provided for the establishment of the Social Development Division whose responsibility included the training of professional social workers and the organization of social agencies.

Considering the teaming social problems in Nigeria, there seem to be no solution for the moment. However, social work education programmes have a task of producing social workers who will be capable of applying professional knowledge and planned skill intervention to the various problem situations in order to assist individuals, groups and communities, and also help promote social development. Ekpe (1997) noted that the purpose of social work education is 
to impart learning of social work practice. Its primary need is for students to emerge as social workers conscious of the value base, capable of intelligently addressing the critical social issues of our day and capable of practicing as professionals. Based on the issues raised above, the main orientation and over-riding concern of this paper are to examine the concept of field work practice, the pre-requisite knowledge, skills and values of social work profession, some salient issues in social work field practice and the role of field instructors in field work practice. It will also proffer a number of measures aimed at enhancing field work practice which is a panacea for social work practice.

\section{The Concept of Field Work Practice}

Field work practice is the crux of social work education. It is the primary medium through which students apply the learned theories to the amelioration of actual life social problems and needs. It offers students in training the opportunity to develop and perfect social work practice skills. According to Hendricks, Finch \& Franks (2005) field work education is the playing field where the knowledge, skills and values of a profession are transmitted. It is the place to understand, apply and integrate theory and practice, and where fundamentals of practice, policy, human behaviour, and research taught in the classroom are tested and consolidated. It is in this context that educational principles are balanced with the reality of agency-based and community based practice and the demands of service delivery to a range of diverse client systems.

Field work practice offers students in training the opportunity to test what they have learnt in the classroom; integrate theory with practice; evaluate the effectiveness of interventions; contend with the realities of social work, political and economic injustice; strive for cultural sensitivity and competence; deliberate on the choices posed by ethical dilemmas; develop a sense of self in practice; and build a connection to and identify with the profession (Larger and Robbin, 2004).

Field education is referred to as the laboratory or testing ground for undergraduate and graduate social work education. From the very beginning of its origins, field work provided an opportunity for both paid and volunteer workers to obtain intimate knowledge of the poor and of actual social and economic conditions. It was believed that only through continuing contact; as a representative of an agency under expert guidance over an extended period of time could a charity worker develop (Sikkema, 2000). Since the establishment of the first formal training programme in social work in 1898, practice and education have remained uneasily interdependent. Initiated by the Charity Organisation Society of New York, classroom teaching was originally intended to support and extend the practice in the field. But by 1960's, field instruction seemed to have come full circle from its original conception. It was viewed by many as a "laboratory extension and support of class experiences" with "the flow of content heavily from class to specially devised field experiences" rather than being reciprocal and interactive (Marshack and Rosenfeld, 2000).

Social work is a professional education. It therefore, includes "on the job" training sequence along with the formal or academic classroom experience. This means that experience trains the person to acquire the skills to become a professional. Medicine has internship, education requires teaching practice and social work has the practicum or field work as the primary place where much of the role definition occurs. Field experience is frequently the first step in the transition from student to professional social worker. The field is where the student acquires specialized knowledge in order to meet the responsibilities of the clients, the community and the society. The field instructors are concerned with both the students and specific setting during the practicum.

\section{Prerequisite Knowledge, Skills and Values for Social Work Profession}

Professions are characterized by the mastery of an extensive body of technical knowledge and concepts of theories that explain knowledge and guide its application to different circumstances (Gaustafson, 2002). In most developing countries, many people who are employed in both government and voluntary agencies and who were trained in non-social work disciplines perform those duties that may fall in the domain of social work. It is not uncommon to find the less informed on the subject mistaking every "good Samaritan" and "philanthropist" for a social worker (Ekpe, 1997). In addition to the above misconception is the fact that other groups and disciplines that concern themselves with the society and individual(s) are referred to as social workers. These include the policeman who is working to maintain law and order in the society, the prison officer who guards the "social misfits" in the prison, the nurse who works with the physicians in curing the sick in the hospitals, the priest whose duty is reconciliation or re-unification of man and his God, the teacher, the psychologist and sociologist among others. It is true that the above mentioned groups and disciplines, and even those not mentioned here concern themselves with society and its varied problems but that does not make them social workers. Thus, while training is the common denominator to these mentioned and not mentioned disciplines, in each of them, their 
respective training and orientation focuses their attention differently on the same object which is the society and the individual in it. Social work equally shares the common trait of training of a particular type which distinguishes it from others (Ekpe and Mamah, 1997).

The preliminary requirement for the practice of social work which is an internationally recognized profession is the acquisition of a generalized and specialized body of knowledge, skills and values. This generalized and specialized body of knowledge, skills and values is usually acquired through a long period of theoretical and practical training.

Council on Social Work Education (2001) identified the knowledge needed for effective social work practice to include:

- Knowledge of case work and group work theory and techniques.

- Knowledge of community resources and services.

- Knowledge of community organization theory and the development of health and welfare services.

- Knowledge of theories and concepts of social welfare administration.

- Knowledge of ethical standards and practices of professional social work.

- Knowledge of theories of group interaction and therapeutic intervention.

- Knowledge of theories of human growth and development and of family and social interactions; among others.

The efficiency of the social work professional depends greatly on his acquired skills. Yuen (2002) observed that the term "skill" has become extremely popular in social work and other helping professions. The skills identified by the Council on Social Work Education (2001) as being essential for the practice of social work include:

- Skill in listening to others with understanding and purpose.

- Skill in eliciting information and in assembling relevant facts to prepare a social history, assessment and report.

- Skill in creating and maintaining professional helping relationships and in using oneself in relationships.

- Skill in observing and interpreting verbal and non verbal behaviour and in using knowledge of personality theory and diagnostic methods.

- Skill in engaging client in effort to resolve their own problems and in gaining trust.

- Skill in discussing sensitive emotional subjects in a non threatening supportive manner.

- Skill in mediating and negotiating between conflicting parties; among others.

The Council on Social Work Education (1992a, 1992b) asserts that among the values and principles that must be infused throughout every social work curriculum are the following;

- Social workers' professional relationships are built on regard for individual worth and dignity and are furthered by mutual participation, acceptance, confidentiality, honesty, and responsible handling of conflict.

- Social workers respect people's right to make independent decisions and to participate actively in the helping process.

- Social workers are committed to assisting client systems to obtain the needed resource.

- Social workers strive to make social institutions more humane and responsive to human needs.

- Social workers demonstrate respect and acceptance of the unique characteristics of diverse population.

- Social workers are responsible for their own ethical conduct, the quality of their practice, and seeking continuous growth in the knowledge and skills of their profession.

\section{Some Salient Issues in Field Work Practice}

Field work practice exposes social workers to both primary and secondary social work agencies. The primary social work agencies are headed by social workers and they include social welfare agencies or centres, rehabilitation centres and reformation centre or agencies among others. Secondary social work agencies on the other hand refer to agencies where social workers are not in charge. These agencies are not headed by the social workers and they include hospitals, schools, communities, prisons and settlement centres among others. However, be it a primary or secondary social work agency, some salient issues in social work field practice include process recording and evaluation among others.

\subsection{Process recording}

Recording and examining process using a variety of techniques provides students with a range of opportunities for reviewing their own reflection in action. Recording stimulates inductive learning and generative theory building on the part 
of students (Graybeal and Ruff, 1995). Process recording involves recording a conversation in some detail. This type of recording is extensively used in social work for training purposes or for helping a student in difficulty to clarify his thinking about a particular situation. It is useful for a student to process record a meeting or some kind of certain types of activity, such as demonstrations. The student's purpose in recording is to help him understand the individual or group.

Baldock (1980) suggested a structure for group process recording along the following lines:

1. Purpose of group event of the worker in attending.

2. Observation about the setting and group members.

3. Content:

(a) A description of how the meeting, social session, etc. began.

(b) Pertinent factual information about decisions taken and reasons for them or other activity according to the type of group event and the responses of the group members and of the worker to these things.

(c) A description of the feeling content of the group event on the part of the members, the worker and any other outsiders.

(d) Notes on how the event ended and, in particular, whether it was on an optimistic note or a pessimistic one and arrangements finalized to ensure that they would be put into effect.

4. Impressions on a more general level.

5. A brief summary of the worker's role in the events, outlining how far this was thought out and followed decisions taken by him before the event.

6. Plan of future action.

\subsection{Evaluation}

At some stage in the work with the group, the student/worker will decide to withdraw. This may mean complete close of content with the group. Alternatively, it may mean that the student/worker will simply stop seeing the group as frequently as he has done during the main period of activity. At the time of withdrawal, there should be a closing report which as far as possible should attempt an evaluation. One could have a project that was one of the action/research or one might have historiographical attempts to reconstruct the development of a project by consulting the records and participating individuals (Baldock, 1980). What is under consideration here is something less ambitious, but still serious, an honest attempt by the student/worker concerned to sit back and look at what happened.

Giving evaluation is one of the most difficult, demanding and complex tasks students/workers have to face; yet, done well, it is one of the most significant spurs to learning (Brookfield, 1990). The process of evaluation provides students/workers with the opportunity to self critique their own practice, an essential component to professional practice, particularly in learning to become autonomous and self-reflective social workers. The written evaluation and the process leading up to it provide us with the platform from which to tackle this fundamental task. The written evaluation is the culmination of the ongoing evaluative process that involves a partnership and collaborative feedback throughout the entire academic year or stipulated period of training. Students take increased responsibility for self evaluation as they advance through their placements, but the emphasis in field instruction is always on mutual responsibility and collaboration. This aims to support students in their professional development, to aid in their ownership of learning achievements and needs, to recognize the instructor's responsibility for the use of power and authority associated with the evaluative role (Hendricks, Finch and Franks, 2005).

Evaluation of progress is crucial during the work. It often occurs while reviewing action steps. Through the skill of evaluating, you engage the client in reviewing progress toward goal attainment. Progress may be indicated by changes in such indicators as goal attainment scales, frequency counts, subjective ratings, or paper-and-pencil instruments. The presence of progress, as well as the rate of change, if any, can be recorded in case notes or presented graphically. When reviewed with clients, evidence of progress may improve self-esteem and increase motivation to undertake further action. Over time, if evaluation reveals no progress, or change in a negative direction, you the client should reconsider the assessment, the contract, and the action steps that you have planned. Obviously, when progress toward achievement is not forthcoming, you need to re-examine the approach to change.

Through the skill of evaluating, you engage the client in examining data that have been collected in accordance with your plan for evaluating progress. You and the client consider the information and determine whether it reflects progress toward goal attainment, no change, or a change in the wrong direction (Cournoyer, 2005).

The process of evaluation is generic, although the specific requirements, terminology, and formats for evaluation may differ. All social work education programmes view evaluation as ongoing educational processes, regardless of their structure and format. According to Hendricks, Finch and Franks (2005), the end of term evaluation usually focuses on: 
- Identification of the specific context of the field placement and of assignments and learning opportunities available in the placement setting;

- Confirmation of student's achievements of stated performance expectation;

- Examples or evidence of student achievement of goals or needs; and

- Identified areas of strength and issues identified for focus of future learning.

\section{The Role of Field Instructors in Field Work Practice}

Field instructors play crucial role in moulding professional Social Workers. Understanding the goal of field instructors provides direction and purpose. Abraham and Fortune (1990) outlined the five elements that constitute a competence base for field instructors:

- A common body of social work knowledge shared by field instructors;

- The capacity of field instructors to conceptualize this knowledge to communicate it effectively;

- The creation of an appropriate climate for learning;

- The clarity regarding the standards for student performance; and

- The ability to evaluate student performance in light of these standards.

The major goal of social work education is to help students achieve a professional identity, "the integration of knowledge, skills and values into a concept of oneself as a professional and into a style of practice consistent with the knowledge, skills and values that define the social work profession" (Hamilton and Else, 1983). The Council on Social Work Education (2001) outlined the steps involved in the achievement of this goal to include:

- Helping students to develop a critically attentive frame of mind and curiosity that is self-directed, autonomous, and creative. This means promoting a questioning stance to theories and intervention strategies by looking at the context of practice and by asking questions as "Why might this be so?" "Who says?" "Under what circumstance?" "Who had been advantaged by it?" (Hartman, 1997).

- Helping students to apply knowledge in a purposeful, planned, problem-solving manner; acquiring a repertoire of specific practice strategies and techniques, promoting the development of professional relationships with other professionals and client systems; and

- Helping students to promote the value of the profession which includes respect for individual orientation and different world views.

The field instructors' task is more than enabling the students to turn knowledge into action. It requires the development of reflection-in-action (Schon, 1987), an acceptance that uncertainly is part of the natural process of the work that critical thinking aids knowledge, and that each intervention provides a rich resource for questioning and enhancing knowledge (Papell \& Skolnik, 1992). Goldstein (1993) observed that a single correct objective solution does not exist for human problems encountered in the field by social workers. Field instructors need help students move from concrete absolutism to a more reflective style that is comfortable with ambiguity. Enabling students to transfer knowledge and apply it differently involves making the information real, making it understood, and making it meaningful to the individual while also transmitting substantive content and promoting the attainment of skills (Gitterman \& Miller, 1977).

The task of field instructors therefore, is to help students break through theoretical and personal boundaries, and cultivate their natural curiosity and spontaneity (Gitterman, 1988). The establishment of a trusting learner/ teacher relationship is essential (Cohen, 2004; Munson, 2001). It is within the field instructor student relationship that students begin to examine their assumptions and to expand their knowledge, skills and values. The degree to which we can be genuine and authentic determines to a large extent, the likely establishment of a positive learning environment. The construction of a conducive environment requires the creation of a space where it is possible to be creative, to engage in the risk-taking implicit in new learning and to examine efforts that fail (Bogo \& Vayda, 1987; Drisko, 2000). Our ability as field instructors to model professional behaviour provides a guide for our students to follow.

Hendricks, Finch and Franks (2005) maintained that our credibility as field instructors is rooted in knowledge, theoretical familiarity and experience. Basic skills such as understanding the elements involved in the establishment of a trusting relationship, neutral methods of exploration and clarification, the importance of probing and the power of initiating change by posing questions that challenges assumptions are directly applicable to methods of teaching students. They however, noted that the application of these clinical skills in field instruction is applied to our role as teachers, not counselors. 


\section{Recommendations}

To improve field work practice to better social work education, the following recommendations are made:

1. The field supervisors should place emphasis on developing a social work practitioner who is able to function more realistically in relation to the numerous problems of the client. To ensure that they require diverse knowledge to cope with the complex of problems, they should be exposed to various agencies.

2. Posting social work students to practice settings would be meaningless without adequate preparations for their integration and absorption. The social work department and the field supervisors should organize workshops/seminars with the agency supervisors. This development will go a long way in educating the agency supervisors on social work education and at the same time help in the integration and absorption of the students on field work practice.

3. Most of the agencies where the student social workers are placed on field practice are ill equipped to fulfill their functions to the clients. It is therefore necessary for the government, religious bodies, non-governmental organizations and public spirited individuals to come to the assistance of these agencies.

4. Home visit is an essential aspect of field work training and practice. However, this aspect seems to be neglected by the field supervisors. To ensure holistic approach to field work practice and social work education, adequate transportation should be made available to facilitate home visits.

\section{Conclusion}

The primary goal of professional education is preparation for practice. Field practice is an essential ingredient in social work education, since it is in field instruction that the student learns to uphold ethical conducts and abhor unethical principles. The outcome of classroom theoretical lessons and field practicum enhances the development of a social work practitioner who functions optimally in relation to social work practice.

We have attempted to examine the concept of field work practice, the prerequisite knowledge, skills and values for field work practice, some salient issues in field work practice and the role of field instructors in enhancing field work practice. Social work is a new profession in Nigeria. This cadre of workers is very much in short supply probably because their role in our national life is not yet fully appreciated even though the need for their services persists. However, exposure at the various societal agencies through field work practice will provide more opportunities for the training of more professionals in this vital area. A paradigm shift in field work practice will bring about an enhancement in social work education. The goal of social work education is to produce professionals that are capable of transforming the Nigerian society by creating awareness on the continued degradation of human value and dignity in the society. Social work has as its objectives the equipping of the practitioners with the necessary technical know-how that enables them to provide the client with the desired services that bring them back into the mainstream of the society.

The study has revealed that for effective social work education, field work practice is indispensable. Through practice in social agencies, social work students in training perfect social work practice skills that enable them to offer services to mankind. Thus, this paper has examined the importance of field work practice in social work education.

\section{References}

Baldock, P. (1980). Library of social work: community work and social work. London: Routledge \& Kegan Paul.

Bogo, M. \& Vayda, E. (1987). The practice of field instruction in social work: Theory and process. Toronto: University of Toronto Press.

Brookfield, S. D. (1990). The skilful teacher: On technique, trust, and responsiveness in the classroom. San Francisco, CA: Jossey Bass.

Cohen, R. I. (2004). Clinical supervision: What to do and how to do it. Belmont, CA: Brooks/ Cole.

Council on Social Work Education (1992a). Curriculum Policy Statement for Baccalaureete Degree Programs in Social Work Education. Alexandria, VA: Council on Social Work Education.

Council on Social Work Education (1992b). Curriculum Policy Statement for Baccalaureete Degree Programs in Social Work Education. Alexandria, VA: Council on Social Work Education.

Council on Social Work Education (2001). Educational Policy and Accreditation Standards. Alexandria, VA: Author.

Cournoyer, B.R. (2005). The Social work skills (4th ed). Belmont, CA USA: Thomson Brooks/Cole.

Drisko, J. W. (2000). Play in clinical learning, supervision and field advising. The Clinical Supervisor, 19 (1), 153 -165.

Ekpe, C. P. \& Mamah, S. C. (1997). Social Work in Nigeria: A colonial heritage. Enugu: Unik Oriental Prints Ltd.

Ekpe, C. P. (1987). Social work education in Nigeria. A seminar paper for the workshop, Mission of Social Work in Nigeria, University of Nigeria Nsukka. 17 th February 17 (pp. $61-72)$. University of Nigeria Press. 
Gaustafson, J. M. (2002). Profession as "Calling". Social Service Review 56 (4) 501 - 516.

Gitterman, A. \& Miller, I. (1977). Supervisors as educators. In F. Kaslow (ed.), Supervision, consultation and staff training in the helping profession. San Francisco: Jossey Bass.

Goldstein, H. (1993). Filed education for reflective practice: A reconstructive proposal. Journal of Teaching in Social Work, 8 (1\&2), 165 -182 .

Graybeach, C. T. \& Ruff, E. (1995). Process recording: It's more than you think. Journal of Social Work Education, 31, 169 - 181.

Hamitton, N. \& Else, J. (1983). Designing field education: Philosophy, structure and process. Sprinfield, IL: Charles C. Thomas.

Hartman, A. (1997). Power issues in social work practice. In A. Katz, A. Lurie \& C. Vidal (eds.), Critical social welfare issues. (pp. 215 226). New York: Haworth.

Hendricks, C. O.; Finch, J. B. \& Franks, C. L. (2005). Learning to Teach, Teach to learn: A guide to social work field education. Virginia: Council on Social Work Education Press.

Lager, P. B. \& Robbin, V. C. (2004). Guest editorial- field education: Exploring the future, expanding the vision. Journal of Social Work Education, 40, $3-11$.

Marshack, E. F. \& Rosenfeld, D. (2000). Agency perspectives on current practice implications for education. Paper presented at the Annual Program Meeting, Council on Social Work Education, Miami, FL.

Munson, C. (2001). Handbook of clinical supervision (3rd ed.). New York: Haworth Press.

Papell, C. P. \& Skolnik, L. (1992). The reflective practitioner: A contemporary paradigm's relevance for social work education. Journal of Social Work Education, 28, $18-26$.

Schon, D. A. (1987). Educating the reflective practitioners. San Francisco, CA: Jossey Bass.

Sikkema, M. (2000). A proposal for an innovation in field learning and teaching. In field instruction in Graduate School Social Work Education: Old problems and new proposals. New York: Council on Social Work Education.

Yuen, F.K.O. (2002). Family health social work practice: A knowledge and skill casebook. New York: Haworth. 